\title{
FLUID FLOW IN PANEL RADIATOR UNDER VARIOUS CONDITIONS - THERMOGRAPHIC VISUALISATION
}

\begin{abstract}
Luděk JANČíK, Jiří BAŠTA•
Abstract: Thermographic investigation of a heating panel radiator under various conditions, especially with various heating water volume flow rate is described in this article. For a radiator type 10-500×1000 TBOE and for two levels of inlet water temperature $\left(75\right.$ and $\left.55{ }^{\circ} \mathrm{C}\right)$ a set of thermal images of surface temperature patterns for various values of heating water volume flow rate was taken. The initial value of flow rate was derived from nominal heating output and recalculated to real conditions. An increase of volume flow rate higher than $15 \%$ over the nominal recalculated value is for the studied cases easily detectable on the resulting thermal images.
\end{abstract}

\section{INTRODUCTION}

Panel radiators are widely used components of heating systems in the region of Central Europe. An important requirement, among others, for an efficient operation of a radiator is maintaining of an optimal value of heating water volume flow rate. This optimal value is calculated from nominal heating output, which is measured in an official test facility and its value must be provided by the manufacturer in the official product data sheet. This nominal value is consequently recalculated for real design conditions according to a valid standard method, e.g. [3].

If the optimal value of volume flow rate is exceeded, the overall heating output is almost not affected; the only remarkable change would be in the temperature difference on the radiator and in higher pressure losses and thus higher energy consumption of the pump. This is a well known fact for heating radiators, more on this phenomenon can be found e.g. in [4].

However, there is very little opportunity to check the real value of the volume flow rate on-site, because a specialized measurement fitting is needed, which represents additional costs for the investor.

Therefore, a method using observation of a heating radiator with a thermal imaging device was investigated, in order to find out the possibilities of this approach for real applications (i.e. solid metering device independent, fast on-site check of radiators' effectiveness related to volume flow rate).

\footnotetext{
- Ing. Luděk Jančík, prof. Ing. Jiři Bašta, Ph.D., FS ČVUT v Praze, Ústav techniky prostředí, Technická 4, 16600 Praha 6, L.Jancik@fs.cvut.cz
}

This is an Open Access article distributed under the terms of the Creative Commons Attribution License 2.0, which permits unrestricted use, distribution, and reproduction in any medium, provided the original work is properly cited. 


\section{DESCRIPTION OF EXPERIMENTAL EQUIPMENT}

Experiments were carried out in laboratories of Department of Environmental Engineering, CTU in Prague. Fundamental components are the radiator, controlled heat source, infra-red (IR) camera and PC with analyzing software [2].

Besides the surface temperature of a radiator measured by the IR camera, additional environment properties, such as ambient air temperature, humidity and reflected temperature, must have been monitored for a correct interpretation of obtained thermal signal. Explanation is related to the basic theory of thermographic measurement, more details can be found for example in [2].

The nominal heating output was recalculated to actual heating output of a radiator using a standard procedure, based on DIN 4703-3 [3], described for instance in [4].

A heat source with a unique design was created for this research project, it is capable of keeping the inlet water temperature $t_{\text {win }}$ within a range of $\pm 0,1{ }^{\circ} \mathrm{C}$. The wall behind the radiator was insulated in order to make the results mutually comparable. Conditions during the measurement were close to nominal values according to the standard CSN EN 442-2 [5] - inlet water temperature of $75^{\circ} \mathrm{C}$, air temperature varied around $20{ }^{\circ} \mathrm{C}$, outlet water temperature was varying according to the air temperature but was close to the nominal value of $65{ }^{\circ} \mathrm{C}$. Sample image of experimental set-up can be seen in Figure 1.

Radiator chosen for this study was of the type 10 (i.e. one panel, no additional surface area enhancement) using top-bottom opposite end (TBOE) connection with dimensions of $500 \times 1000 \mathrm{~mm}$ (height $\times$ length). Its basic properties, provided by the manufacturer, can be seen in [6].

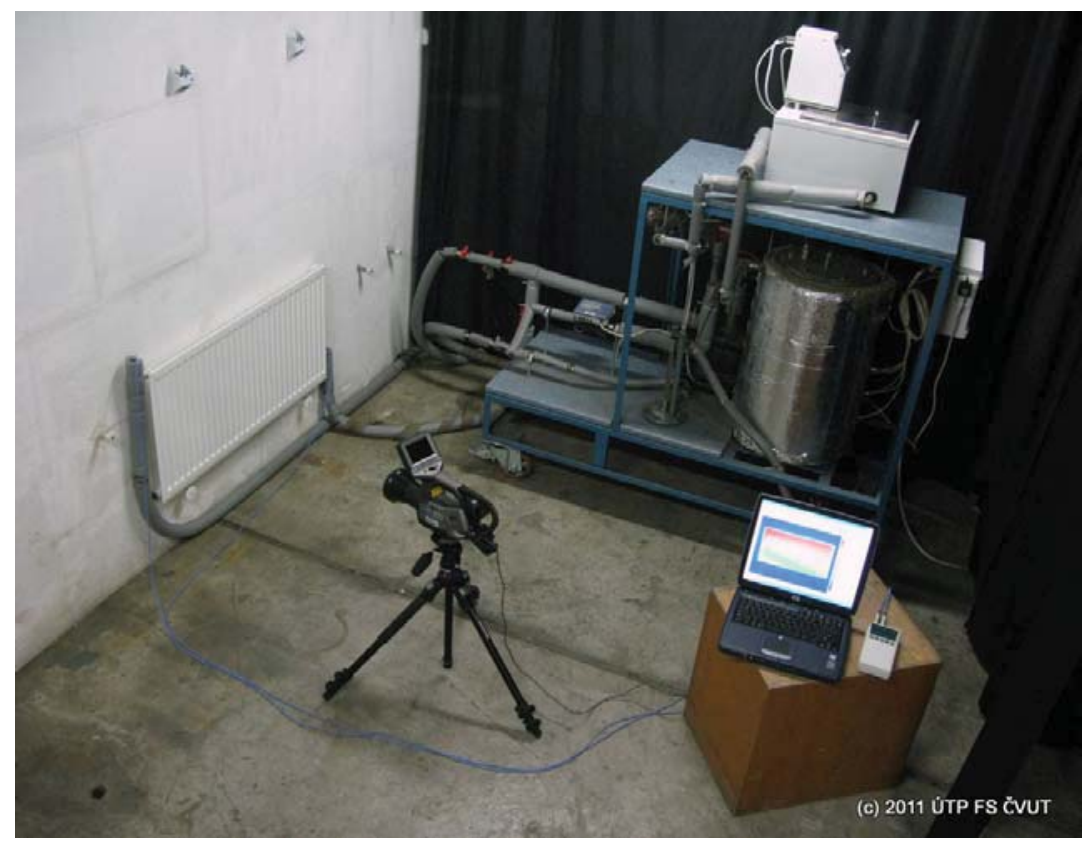

Figure 1: Experimental facility. 


\section{Results}
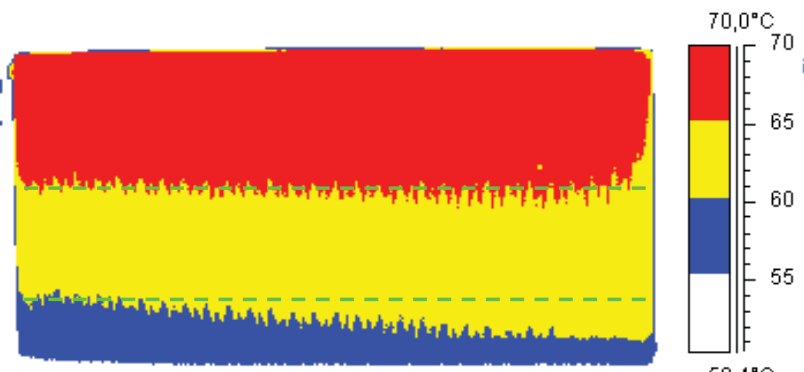

$V_{w}=0,043 \mathrm{~m}^{3} / \mathrm{h}$

$75,7 / 62,6 / 21,9^{\circ} \mathrm{C}$

$50,4^{\circ} \mathrm{C}$
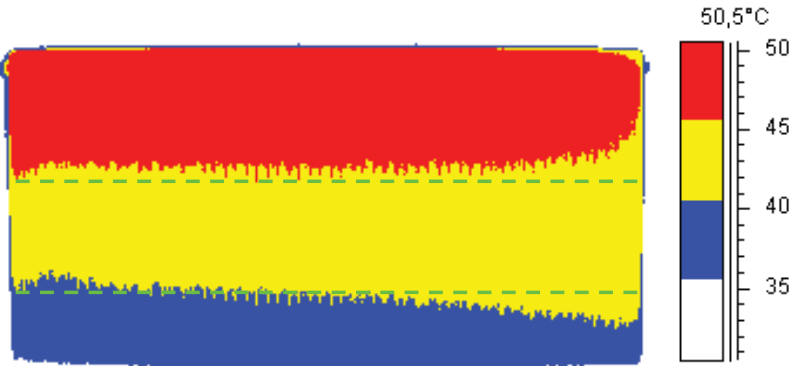

$V_{w}=0,022 \mathrm{~m}^{3} / \mathrm{h}$

$30,5^{\circ} \mathrm{C}$

$54,5 / 40,0 / 20,8^{\circ} \mathrm{C}$

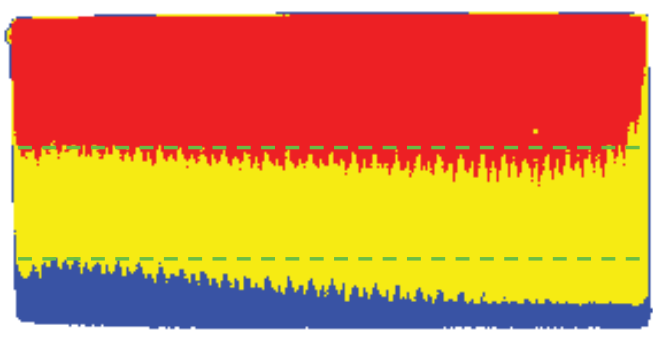

$V_{w}=0,047 \mathrm{~m}^{3} / \mathrm{h}(+9 \%)$

$75,9 / 63,9 / 22,1^{\circ} \mathrm{C}$

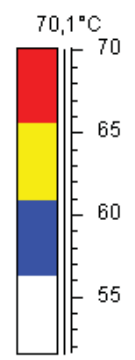

$51,6^{\circ} \mathrm{C}$
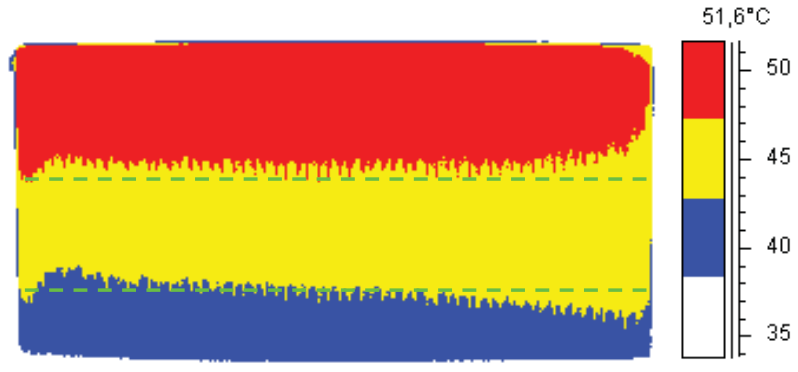

$V_{w}=0,024 \mathrm{~m}^{3} / \mathrm{h}(+9 \%)$

$33,8^{\circ} \mathrm{C}$

$55,8 / 42,8 / 20,8^{\circ} \mathrm{C}$

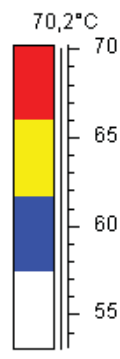

$V_{w}=0,051 \mathrm{~m}^{3} / \mathrm{h}(+19 \%)$

$76,0 / 64,7 / 22,3^{\circ} \mathrm{C}$

$53,1^{\circ} \mathrm{C}$

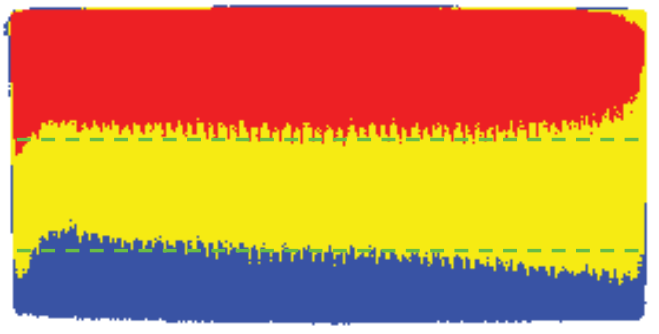

$V_{w}=0,027 \mathrm{~m}^{3} / \mathrm{h}(+23 \%)$

$56,2 / 44,2 / 20,8^{\circ} \mathrm{C}$

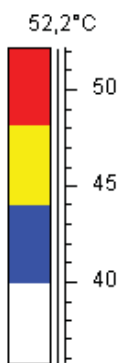

$35,8^{\circ} \mathrm{C}$

$71,2^{\circ} \mathrm{C}$
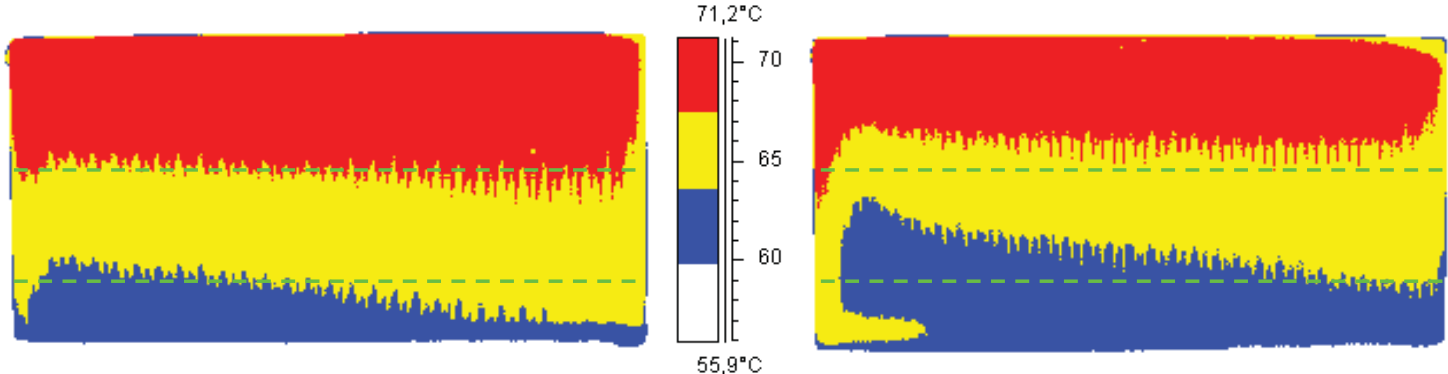

$54,1^{\circ} \mathrm{C}$

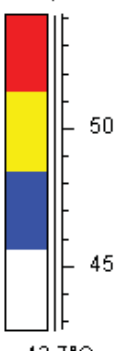

$$
V_{w}=0,064 \mathrm{~m}^{3} / \mathrm{h}(+49 \%)
$$

$77,0 / 66,8 / 22,3^{\circ} \mathrm{C}$

$$
\begin{gathered}
V_{w}=0,043 \mathrm{~m}^{3} / \mathrm{h}(+95 \%) \\
58,0 / 49,7 / 20,7^{\circ} \mathrm{C}
\end{gathered}
$$

Figure 2: Surface temperature patterns on radiator 10-500x1000 TBOE. Left column for $t_{\text {win }}=75^{\circ} \mathrm{C}$, right column for $t_{\text {win }}=55^{\circ} \mathrm{C}$. Water inlet is always located in the top left corner, outlet in the lower right corner. 


\section{EXPERIMENTAL METHOD}

Behavior of the radiator was studied for two levels of inlet water temperature $t_{\text {win }}$. These levels are $75^{\circ} \mathrm{C}$, which corresponds to the nominal conditions according to CSN EN 442-2 [5] $\left(75 / 65 / 20{ }^{\circ} \mathrm{C}\right.$ - i.e. $t_{\text {win }} / t_{\text {wout }} / t_{\text {air }}$ - water inlet/water outlet/ambient air temperature) and $55^{\circ} \mathrm{C}$, which corresponds to design conditions for low temperature heating systems $\left(55 / 45 / 20^{\circ} \mathrm{C}\right)$. Respective heating outputs for these conditions can be found in technical data sheet of the radiator's manufacturer [6].

Based on these nominal heating outputs, volumetric flow rates for desired $t_{\text {win }}$ and real ambient air temperature were calculated. After reaching a steady state with volume flow rate derived from nominal heating output, the volume flow rate was gradually changed using a STAD type control valve.

Resulting thermal images, each with actual volume flow rate and temperature conditions can be seen in Figure 2 .

\section{Discussion}

As can be seen in Figure 2, the increase of volume flow rate affects the resulting surface temperature field. Auxiliary lines have been added to images for easier comparison. The main change occurs at the lower left corner of the radiator - the higher flow rate the sharper "tooth" disruption in the temperature field.

Very interesting comparison provides the first image for $t_{\text {win }}=75^{\circ} \mathrm{C}$ (top left) and the last image for $t_{\text {win }}=55{ }^{\circ} \mathrm{C}$ (bottom right). The volume flow rate is the same for both cases $\left(V_{w}=0,043 \mathrm{~m}^{3} / \mathrm{h}\right)$, the only difference is the inlet water temperature. For $t_{w i n}=75^{\circ} \mathrm{C}$, the value of $0,043 \mathrm{~m}^{3} / \mathrm{h}$ corresponds with the nominal and thus optimal value for this temperature range. For $t_{\text {win }}=55^{\circ} \mathrm{C}$, the value of $0,043 \mathrm{~m}^{3} / \mathrm{h}$ is almost two times higher than the recalculated nominal flow rate of $0,022 \mathrm{~m}^{3} / \mathrm{h}$ for this case, which explains the radical difference between these two images of temperature field.

It should be mentioned, that all conclusions are based on a full set of thermal images for known values of volume flow rate. For real applications, there will be just one image of a radiator's temperature field for evaluation of the actual flow rate related effectiveness, which would require more sophisticated methodology, probably based on higher number of studied cases.

\section{CONCLUSION}

Based on obtained thermal images for studied cases (radiator 10-500x1000 TBOE, inlet water temperatures 75 an $55^{\circ} \mathrm{C}$ ), it can be stated, that changes of volume flow rate on principle affect the surface temperature pattern observed by the infrared camera.

The main change was observed at the left bottom side of a radiator (water inlet was from the top left corner). The tooth-shaped disruption of temperature field is easily visible for flow rates higher than $15 \%$ compared to nominal value recalculated to real conditions. 


\section{REFERENCES}

[1] Jancik L., Basta J.: Thermographic Measurement of Dynamic Behaviour of Panel Radiators, Proceedings of Experimental Fluid Mechanics 2008, TU Liberec, 2008, p. 61 - 71 ISBN 978-80-7372-417-7

[2] FLIR Systems. ThermaCAM Researcher : User's manual. Rev. a74, 2004. 146 p.

[3] DIN 4703-3. Heating Appliances - Part 3: Conversion of the Standard Thermal Output.

[4] Basta, J.: Heating Surfaces. In Czech: Otopne plochy. Prague: 2001. 328 p. ISBN 80-01-02365-6.

[5] CSN EN 442-2:1996 Radiators and Convectors - Part 2: Test Methods and Rating.

[6] Korado a.s., Ceska Trebova, Czech Republic. Product information. Available online: http://www.korado.com/en/products/radik/review-of-models/radikklasik/index.shtml 